\title{
A contrastive study on thanking in Arabic dialects and English
}

\section{Rana Jamal Al-Maznaei}

Faculty of Foreign Studies, Linguistics, Nanjing University of Science and Technology, China r.jamal22@yahoo.com 


\title{
A contrastive study on thanking in Arabic dialects and English
}

\author{
Rana Jamal Al-Maznaei* \\ Faculty of Foreign Studies, Linguistics, Nanjing University of Science and Technology, China \\ E-mail: r.jamal22@yahoo.com
}

\begin{abstract}
Cross-Cultural Pragmatics (CCP) is a field of study that focuses on the interaction of people from various cultures. It is to clarify cultural distinctions between languages that acquire meaning through context and sociocultural embedding, resulting in a pragmatic communication failure. This study determines whether the Arabic language, because of dialectical variation, contains more thanking methods than English. Additionally, it aims to investigate the politeness strategies used by Arabs and native English speakers. Besides, it aims to determine whether contextual variables affect thanking expressions. The data collection instrument was an open-ended questionnaire in two versions Arabic and English. The results were then analyzed quantitatively using SPSS software version 26.0, following Cheng's classification of thanking. The findings indicate that dialectical diversity is not associated with an increase in thanking strategies that are more prevalent in English. Additionally, religion affects the Arabs speaking, their manner of thanking does not exclude religious expressions, which are their preferred method of expressing their politeness and gratitude. In terms of the politeness strategies, both native Arabic and English speakers preferred negative politeness to positive politeness, which focuses on minimizing the FTA's particular imposition. Concerning contextual variables such as familiarity and social status, both affect how the thanking speech act is performed. It will be worthwhile to investigate thanking in Arabic and English with a specific factor such as social distance. Additionally, it is beneficial to examine thanking in Arabic dialects regarding civilization's cultural influence and the dialect's proximity to standard Arabic.
\end{abstract}

Keywords: Thanking strategy; religious formulas as a form of politeness; Negative politeness.

\section{Introduction}

This research focuses on semantics and pragmatics fields, in which speech act theory comprises both areas. As cited in Burkhardt (1990), Katz (1980) states that "pragmatics is performance theory at the semantic level." According to this position, both index expressions and speech's study belongs to semantics and pragmatics partially. Speech acts are one of the main elements in cross-cultural and interlingual pragmatics. Several studies of speech acts have been conducted in terms of politeness strategies, including thanking (Ohashi, J. 2013; Saberi, K. 2012), requesting (Peterson, 2010; Alakrash \& Bustan, 2020), apologizing (Al-Adaileh, 2007; Abbas at al., 2019), offering (Yaqubi et al., 2016; Mansor, 2017). According to Searle et al. (1980), the premise of speech theory is that the smallest unit of human communication is not a sentence or other words, but rather the performance of specific forms of behaviour, such as statements, requests, commands, describing, explanations, apologies, thanking, congratulations, etc.

Thanking is classified by Searle (1969) as an expressive illocutionary act. It is the speaker's expression of gratitude for the hearer's involvement in a prior action. Additionally, Leech (1983) categorizes thanking as a convivial speech act that expresses politeness and good manners. While it has thanking function, it may rely on the speaker's intentions to involve different speech acts (functions) in other contexts. Jumanto et al. (2017) stated

\footnotetext{
* Corresponding author

Email address: r.jamal22@yahoo.com (Rana Al-Maznaei)

DOI: https://doi.org/10.31559/BAES2021.6.1.1
} 
that politeness theories on the interpersonal face or social face are important for interpersonal interactions or social interactions. These interactions can be verbal or non-verbal. Verbal forms in speech such as thanking, apology, or greeting. Non-verbal forms may be understood visually or situationally through facial expression, eye contact, gestures, or physical movement. As with politeness ideology, both verbal form and non-verbal form or actions should be elaborated so that they are perceived as conveying politeness. In Blum-Kulka and Olshtain (1984) opinion, cross-cultural research showed that various cultures adhere to specific standards of appropriateness. Barešová (2008) stated that each culture has a different perception of what is polite, and each language has various devices for expressing politeness. Thus, politeness is regarded as a universal phenomenon found in all languages.

Theoretically, this research is likely to fill a gap in the literature on thanking in Arabic and English and add to the literature on politeness and contrasting socio-pragmatics in general. Besides, identifying the thanking strategies' language functions is a step forward in both cultures to recognize and connect them to the universal language. Practically, cross-cultural differences play a vital role in speech act performing and may lead to crosscultural miscommunication, resulting from lacking socio-pragmatic knowledge. In accordance with Wierzbicka (2003), in modern multi-ethnic and multi-racial societies, more people of many different cultural backgrounds must live together. As a sequence, this study will make language learners aware of the socio-pragmatic norms in which pragmatic meanings reflect the specific local language use requirements. Knowing when to speak, what to say to whom, and what circumstances will lead to effective communication in a second language rather than relying on one's native culture. Besides that, it may provide insights to scholars and learners of Arabic and English in further studies.

\subsection{Previous studies}

Al-Shaer (2013) examined the speech act of thanking and promising in American English and Palestinian Arabic. He used corpora of authentic and contextualized spontaneous spoken utterances for both English and Arabic. The English examples were collected from Tillitt and Bruder's book and Arabic from Modern Standard Arabic and daily social interactions. The findings revealed that thanking in Arabic uses entirely different expressions in informal situations than it does in English. In most cases, religious formulae are found in the form of supplications that begin with an explicit reference to Allah (God). Regarding the subject of his research, he did not specify the speech acts that would be examined, instead referring to them as "Speech Acts." Additionally, utilizing English corpora from a book may not be an appropriate method for data collection. Al-Bataineh (2013) examined the use of Jordanian and American native speakers (Congratulating, Thanking, and Apologizing). He used Discourse Completion Task to collect the data. The findings revealed that both languages employed comparable politeness techniques but to differing degrees of frequency and realization. Additionally, it demonstrated that religion impacts interactions in Arabic and that religious expressions denote politeness in almost all social contexts. Al-Talhi (2014) examined the speech act of thanking strategies used by Hijazi females. She also collected the data through Discourse Completion Task. The findings revealed interesting differences in how Hijazi females communicate and reacted to gratitude depending on the value received. By focusing exclusively on gender factor, the study's data set would be constrained. The studies had examined the speech act of thanking in Arabic, which were all dialects such as (Hijazi, Palestinian, Jordanian dialect, etc.). However, there was no interest in studying thanking in the Arabic language in general without focusing on a specific dialect, as this study will do.

\subsection{Research Questions}

Question 1: Does the variety of Arabic dialects make it has more thanking strategies than English?

Question 2: What are the most politeness strategies used by Arabic and English native speakers?

Questions 3: Does thanking expressions influenced by contextual variables as familiarity and social status?

\section{Brown and Levinson Face theory (1987)}

For many years, among the many studies of politeness conducted in various cultures, Brown and Levinson's politeness theory has been highly influential (Watts et al., 2005). Al-Abdali (2019) claimed that it is one of the most comprehensive and empirically based theories of pragmatic politeness. It covered a broad range of fields and proved to be highly applicable in the majority of cultures. In 1987, Brown and Levinson presented their version of the face as "the public self-image" that others must preserve during the interaction. Their concept of 'face' is derived from Goffman's (1967), who associates it with notions of embarrassment or humiliation or losing face. As a result, their model is based on recognizing a person's free individuality in social interaction. They maintained that the face is a highly emotional object that can be lost, preserved, or improved and must be continuously attended to during interactions. Brown and Levinson introduced the idea of a face in this context, which indicates that individual wishes to preserve their self-image, i.e., positive, and negative face, during an interaction. In addition, they invented the meaning and role of politeness in communication and provided a list of politeness strategies. 


\subsection{Face and face-threatening act}

Individuals from all cultures communicate with an awareness of their self-image. Protecting one's face is critical for interacting well with others, even if participants may not know it. A "face-threatening act" (FTA) has the potential to make someone losing face or causing it to be damaged in some way. FTAs are frequently softened through politeness in ordinary interaction. Politeness can be conveyed in two ways: through "positive politeness" (e.g., "please") or through "negative politeness" (e.g., "I'm sorry"), both of which are intended to allow the other person to avoid imposition. According to Brown and Levinson (1987:67), FTAs can threaten negative and positive faces (e.g., complaints, interruptions, threats, intense expressions of emotion, requests for personal information). When FTA is an unavoidable part of an interaction, the speaker may employ face-saving. A face-saving act is one that significantly minimizes or removes the threat of losing or damaging one's face.

\subsection{Politeness Strategies}

\subsubsection{Strategies of Positive Politeness}

Brown and Levinson claimed that positive politeness is a redress addressed to the concerns about positive face. The speaker satisfies the hearer's positive face by pursuing some of the hearer's desires. This approach is frequently employed to minimize the distance between the speaker and the hearer. They claimed that positive politeness utterances are used metaphorically to signify a degree of common ground or desire sharing even between strangers who regard themselves as somewhat similar for the interaction. For the same reason, positive politeness strategies can be used not only for FTA redress but also for social accelerants. The speaker implies that by employing them, they intend to get closer to the hearer. They have classified the positive politeness strategy into fifteen sub-strategies.

1. Noticing hearer's interests, wants, needs and goods

For example: "You must be exhausted; it has been a long time since you did your duties. How about taking a break?".

2. Exaggerating interest, approval, sympathy with the hearer

For example, "What an amazing car you have!".

3. Intensifying interest to the hearer

For example, "I saw a car accident in the next street, and two people were lying on the ground, and then the police came...."

4. Using in-group identity markers

For example, "Help me to open this bottle, dear".

5. Seeking agreement

A: Tommy will go to the USA this weekend!

B: To the USA!

6. Avoiding disagreement

For example, "Yes, I really like your new bag!".

7. Presupposing to raise and assert a common ground

A: "Oh, this dress looks awfully, mom."

B: "Yes, darling, it looks bad, I know."

8. Joking

For example, "How if I took all these chocolates now".

9. Presupposing speaker's knowledge of and concern for the hearer's wants

For example, "I know you don't like sweets, but this cake is really delicious".

10. Offering, promising

For example, "I will allow you to invite your friends next week".

11. Being optimistic

For example, "You will attend my party at the weekend, I hope".

12. Including both speaker and hearer in the activity

For example, "Let's have a coffee".

13. Giving or asking for reasons

For example, "You need to wear a jacket; it is about to rain".

14 . Assuming or asserting reciprocity

For example, "I will give you some money if you help me clean the house".

15. Giving gifts to the hearer (goods, sympathy, understanding, cooperation)

For example, "I am proud of your success in your studies".

\subsubsection{Strategies of Negative Politeness}

Brown and Levinson (1987) defined negative politeness as an action taken to redress the addressee's negative face, his desire for unrestricted action and attention. It shows that the redress is directed at the hearer "s autonomy and freedom of action. Negative politeness is concerned with minimizing the FTA's particular 
imposition. This technique is based on the speaker's desire to impose on the listener. They classified the strategy of negative politeness into ten sub-strategies.

1. Being conventionally indirect

For example, "Can you please open the window?".

2.Using hedges

For example, "Could you give me a little bit of sugar?".

3. Being pessimistic

For example, "You couldn't possibly lend me your car, could you?".

4. Minimizing the imposition

For example, "Could you give me a little bit of sugar?".

5. Giving deference

For example, "Excuse me, miss, would you mind if I open the window?".

6. Apologizing

For example, "I am sorry to disturb you; I want to ask you if you can give me more time for the final paper?"

7. Impersonating speaker and hearer

For example, "Do this for me".

8. Stating the FTA as a general rule

For example, "The United States expresses regrets over the occurrence of the incident."

9. Nominalizing

For example, "Your good performance on the volunteer work in the association impressed us favourably".

10. Going on record as incurring debt, or as not an indebting hearer

For example, "I could easily buy it for you."

FTA is calculated according to three sociological variables, as defined by Brown and Levinson (1987:74).

1) Social distance between $S$ and $H$ (D)

2) Relative power of $H$ over $S$ or $S$ over $H(P)$

3) Weight of imposition in each culture (W)

They added that D, P, and R are only interesting to the degree that the actors believe they share

common knowledge about the values of these variables. Thus, these variables are not intended to represent sociologists' assessments of actual power, distance, and so on, but rather to represent actors' assumptions of such judgments, which are assumed to be mutually accepted, at least within certain bounds. The present study will examine the effect of two variables on the degree of politeness for utterances: social distance and relative power (social status).

\section{Research methodology}

\subsection{Participants}

The participants in this study consisted of two groups, Arabs from (Syria, Egypt, Yemen, Algeria, Tunisia, Kuwait, Sudan, Palestine, Morocco, Jordan, Libya, Iraq, Somal and Saudi Arabia) and English native speakers including (USA and UK), with 200 participants per group. Most of the Arabs were students in Chinese universities, and English native speakers were also students in their countries or overseas.

\begin{tabular}{|c|c|c|c|}
\hline Category & Profile & Total Number & $(\%)$ \\
\hline & Arabs Male & 99 & 49 \\
\hline \multirow[t]{5}{*}{ Gender } & Arabs Female & 101 & 51 \\
\hline & English Native Speaker Male & 47 & 23 \\
\hline & English Native Speaker Female & 153 & 77 \\
\hline & $18-24$ & 126 & 63 \\
\hline & $25-30$ & 27 & 13 \\
\hline \multirow[t]{5}{*}{ Arabs Age } & $31-35$ & 21 & 10 \\
\hline & $36-40$ & 9 & 5 \\
\hline & 41 above & 17 & 9 \\
\hline & $18-24$ & 22 & 11 \\
\hline & $25-30$ & 79 & 39 \\
\hline \multirow[t]{3}{*}{ English Native Speakers Age } & $31-35$ & 84 & 42 \\
\hline & $36-40$ & 15 & 8 \\
\hline & 41 above & 0 & 0 \\
\hline
\end{tabular}




\begin{tabular}{|c|c|c|c|}
\hline & Bachelor & 67 & 33 \\
\hline & Master & 76 & 37 \\
\hline \multirow[t]{4}{*}{ Arabs Educational Level } & $\mathrm{PhD}$ & 44 & 22 \\
\hline & Postdoctoral & 7 & 4 \\
\hline & Others & 7 & 4 \\
\hline & Bachelor & 126 & 63 \\
\hline \multirow[t]{9}{*}{ English Native Speakers Educational Level } & Master & 47 & 24 \\
\hline & $\mathrm{PhD}$ & 8 & 4 \\
\hline & Postdoctoral & 18 & 9 \\
\hline & Others & 0 & 0 \\
\hline & Yemen & 96 & 48 \\
\hline & Egypt & 33 & 16.5 \\
\hline & Syria & 18 & 9 \\
\hline & Morocco & 9 & 4.5 \\
\hline & Algeria & 8 & 4 \\
\hline \multirow{9}{*}{ Arabs Nationality } & Sudan & 7 & 3.5 \\
\hline & Iraq & 7 & 3.5 \\
\hline & Palestine & 6 & 3 \\
\hline & Libya & 6 & 3 \\
\hline & Jordan & 3 & 1.5 \\
\hline & Tunisia & 2 & 1 \\
\hline & Kuwait & 1 & 0.5 \\
\hline & Somal & 1 & 0.5 \\
\hline & Saudi Arabia & 3 & 1.5 \\
\hline \multirow[t]{2}{*}{ English Native Speakers Nationality } & United Kingdom & 114 & 57 \\
\hline & United States & 86 & 43 \\
\hline
\end{tabular}

\subsection{Instrument}

The current study collected data using DCT, a method that is frequently used in intercultural pragmatics. Blum-Kulka established the DCT as a method for investigating speech acts. Since then, DCT has established itself as a standard method for collecting data in the study of speech acts (Beebe \& Cummings, 1996). As a result, DCT was considered the most appropriate method for studying speech acts and collecting the data for this study. The present study used a two-part instrument: a demographic survey and a DCT that contained ten items that varied according to the interlocutor's familiarity and social status. Familiarity (i.e., social distance) and social status (i.e., power) were chosen as the primary variables affecting speech behavior in a cross-cultural pragmatics study (Brown \& Levinson, 1987). There were two versions of the instrument, one in Arabic and the other in English. The technique of back translation was used to ensure that these two versions were equivalent in translation.

\subsection{Procedure}

Quantitive analysis has been used in this study. It is the numerical analysis of data collected via polls, questionnaires, and surveys and the manipulation of pre-existing statistical data through computational techniques. The DCT with the two versions was distributed to Arab and English native speakers. After both groups achieved 200 participants, data were collected and classified according to Cheng's classification (2005) and (2010) of thanking strategies that consisted of nine strategies. Then, one more strategy was added by the researcher, which is wishing (religious formulas). Finally, data has been analyzed using SPSS statistical program version 26.0 then presented in figures, and detailed subjective analysis.

\subsubsection{Thanking classification}

1. Thanking

Thanking strategy consists of three sub-categories:

(a) By using the word "thank".

- Thanks, thank you.

(b) By thanking and stating the favour. 
- Thank you for your support.

(c) by thanking and mentioning the imposition caused by the favour.

2. Appreciation

This strategy has two sub-categories:

(a) Using the word appreciate without more explanation.

- I appreciate it.

(b) Using the word appreciate and mentioning the imposition caused by the favour.

- I am quite appreciated your help.

3. Positive feelings

This strategy has three sub-categories:

(a) By showing a positive impression towards the favour giver (hearer)

- You are a lifesaver.

(b) By expressing a positive reaction on the object of the favour

- The notebook was very helpful

(c) By showing a positive reaction to the outcome of the favour

- I'll keep you informed of what will happen.

4. Apologizing

This strategy has five sub-categories:

(a) By using only apologizing words

- Sorry or apologize.

(b) By using apologizing words and stating the favour of the fact

- Sorry for being late.

(c) By using apologizing words and reference the imposition posed by the favour

- My apologies for disturbing you on holiday.

(d) By self-criticism or blaming

- It is my fault to keep you waiting.

(e) By expressing embarrassment

- This is an embarrassment.

5. Recognition of imposition.

By acknowledging the imposition.

- I know you did not have to allow me extra time.

6. Repayment

This strategy has three sub-categories

(a) By offering or promising service, money, food or goods.

- Can I buy you coffee ortea?

(b) Feeling indebted

- I owe you one

(c) Promising future self-improvement

- It won't happen again

7. Alerters

Alerters are items that serve as an attention-getter or address terms preceding the actual speech act to catch the listener's interest. The alerters include:

(a) Attention getter (e.g. Hey, Excuse me, Well, wow, oh, hmm)

(b). Title (e.g. Dr., Professor! Sir!)

(c). Name (e.g. John, Mary)

(d). Endearment term: (Honey, Dear)

8. No gratitude (showing relief)

- Thank goodness.

9. Wishing (Religious formulas)

- May God's mercy be on your parents'.

10. Others

This strategy has four sub-categories under the other strategy:

(a). Here statement (e.g. Here's your notebook!)

(b). Small talk (e.g. I will pay you once I get my wallet)

(c). Leave-taking (e.g. Have a nice holiday!)

(d). Joking (e.g. Don't forget to pay again next time)

\section{Results}

\subsection{Comparison of Thanking Strategies in Arabic and English}

The findings in Tables 2 and 3 indicate that participants in both ENS and ANS used the Thanking strategy frequently, at a rate of $83.9 \%$ and $68.3 \%$, respectively. ENS employed an appreciation strategy, with $13.7 \%$. ANS, 
on the other hand, used only 2.65\%. According to Nelson et al. (1996), Arabs avoid appreciation markers because they consider them flat, unpleasant, and insufficient for conveying an appreciation response consistent with their preference for lengthy eloquent phrases. Positive feelings were used in the same way for ENS and ANS, with 18.3\% and 17.9\%, respectively. Concerning Apologizing strategy, 3.6\% and 4.3\%, respectively, were used for ENS and ANS. It was used explicitly as "sorry to bother you". Implicitly, it was used in embarrassment phrases and selfblaming such as "I am so embarrassed, I'll get it next time".The two groups used recognition of imposition the least frequently, at $0.6 \%$ and $0.05 \%$, respectively. Both groups used a similar repayment strategy, with $10.75 \%$ and $5.85 \%$, respectively. ENS employed the Alerters strategy with a frequency of $6.9 \%$, significantly higher than ANS's $0.8 \%$. No gratitude strategy (by showing relief) was used infrequently $0.4 \%$ and $1.1 \%$, respectively, for both ENS and ANS, such as "Thank goodness". The reason for ANS's higher frequency than ENS's is that it is a phrase uttered in response to God's adoration and mercy, and it is a declaration of gratitude to God. It is related to the religious effect. ANS frequently used the wish strategy, with a frequency of $32.7 \%$, as "May God bless you" and "may God reward you and grant you good health." In contrast, ENS used it infrequently $0.3 \%$. The reason for this is that religion has a strong influence on how Arabs speak their language. This is due to the religious influence on Arab speech, where religious formulas were frequently used as a primary strategy such as "God protect you," or in conjunction with another strategy, such as "Thank you, may God reward you and keep you safe from harm." ENS employed other strategy at a higher rate than ANS at $11.6 \%$ and $4.65 \%$, respectively. It was used in complement with thanking for both groups, whether it was small talk such as "Can I pay you later?" or leave-taking such as "Have a nice holiday."

Table (2): Frequency of using Thanking Strategies in Arabic Language (N=200)

\begin{tabular}{|c|c|c|c|c|c|c|c|c|c|c|c|}
\hline $\begin{array}{l}\text { Situation } \\
\text { Number }\end{array}$ & a & b & c & d & e & $f$ & g & h & i & $\mathbf{j}$ & Total \\
\hline & 150 & 2 & 16 & 1 & 0 & 7 & 0 & 0 & 66 & 2 & 244 \\
\hline \multirow{2}{*}{ S1 } & $75 \%$ & $1 \%$ & $8 \%$ & $0.5 \%$ & $0 \%$ & $3.5 \%$ & $0 \%$ & $0 \%$ & $33 \%$ & $1 \%$ & $100 \%$ \\
\hline & 129 & 1 & 31 & 9 & 0 & 11 & 0 & 1 & 53 & 50 & 285 \\
\hline \multicolumn{12}{|l|}{ S2 } \\
\hline & 134 & 5 & 44 & 7 & 0 & 19 & 1 & 3 & 71 & 5 & 289 \\
\hline & \multicolumn{5}{|c|}{ S3 } & $9.5 \%$ & $0.5 \%$ & $1.5 \%$ & $35.5 \%$ & $2.5 \%$ & $100 \%$ \\
\hline & 143 & 5 & 30 & 15 & 0 & 26 & 2 & 1 & 56 & 14 & 292 \\
\hline \multicolumn{12}{|l|}{ S4 } \\
\hline & 108 & 3 & 71 & 12 & 1 & 4 & 7 & 2 & 52 & 0 & 260 \\
\hline \multicolumn{12}{|l|}{ S5 } \\
\hline & 168 & 4 & 17 & 12 & 0 & 2 & 2 & 1 & 37 & 13 & 256 \\
\hline \multicolumn{12}{|l|}{ S6 } \\
\hline & 163 & 19 & 24 & 28 & 0 & 7 & 0 & 0 & 31 & 2 & 274 \\
\hline \multicolumn{12}{|l|}{ S7 } \\
\hline & $81.5 \%$ & $9.5 \%$ & $12 \%$ & $14 \%$ & $0 \%$ & $3.5 \%$ & $0 \%$ & $0 \%$ & $15.5 \%$ & $1 \%$ & $100 \%$ \\
\hline & 132 & 3 & 47 & 0 & 0 & 20 & 0 & 2 & 87 & 1 & 292 \\
\hline S8 & $66 \%$ & $1.5 \%$ & $23.5 \%$ & $0 \%$ & $0 \%$ & $10 \%$ & $0 \%$ & $1 \%$ & $43.5 \%$ & $0.5 \%$ & $100 \%$ \\
\hline & 132 & 2 & 31 & 1 & 0 & 4 & 3 & 10 & 98 & 6 & 287 \\
\hline & \multicolumn{5}{|c|}{ S9 } & $2 \%$ & $1.5 \%$ & $5 \%$ & $49 \%$ & $3 \%$ & $100 \%$ \\
\hline \multirow{2}{*}{ S10 } & 107 & 9 & 47 & 1 & 0 & 17 & 1 & 2 & 103 & 0 & 287 \\
\hline & $53.5 \%$ & $4.5 \%$ & $23.5 \%$ & $0.5 \%$ & $0 \%$ & $8.5 \%$ & $0.5 \%$ & $1 \%$ & $51.5 \%$ & $0 \%$ & $100 \%$ \\
\hline \multirow{2}{*}{ Total } & 1,366 & 53 & 358 & 86 & 1 & 117 & 16 & 22 & 654 & 93 & 2,766 \\
\hline & $68.3 \%$ & $2.65 \%$ & $17.9 \%$ & $4.3 \%$ & $0.05 \%$ & $5.85 \%$ & $0.8 \%$ & $1.1 \%$ & $32.7 \%$ & $4.65 \%$ & $100 \%$ \\
\hline
\end{tabular}

Note: $a=$ Thanking, $b=$ Appreciation, $c=$ Positive feelings, $d=$ Apology, $e=$ Recognition of imposition, $f=$ Repayment, $g=$ Alerters, $h=$ No gratitude, $i=$ Wishing, $j=$ others.

Table (3): Frequency of using Thanking Strategies in English Language (N=200)

\begin{tabular}{|c|c|c|c|c|c|c|c|c|c|c|c|}
\hline $\begin{array}{c}\text { Situation } \\
\text { Number }\end{array}$ & a & b & c & d & e & f & g & h & i & $\mathbf{j}$ & Total \\
\hline & 188 & 23 & 34 & 0 & 0 & 19 & 1 & 0 & 0 & 7 & 272 \\
\hline & \multicolumn{9}{|c|}{ S1 } & $3.5 \%$ & $100 \%$ \\
\hline & 158 & 8 & 21 & 12 & 1 & 19 & 6 & 0 & 0 & 125 & 350 \\
\hline \multicolumn{12}{|l|}{ S2 } \\
\hline & 169 & 37 & 44 & 1 & $\begin{array}{c}0.3 \% \\
0\end{array}$ & $\begin{array}{c}.5 \% \\
36\end{array}$ & $\begin{array}{c}3 \% \\
0\end{array}$ & $0 \%$ & 0 & $\begin{array}{c}02.5 \% \\
9\end{array}$ & 296 \\
\hline \multicolumn{12}{|l|}{ S3 } \\
\hline & $84.5 \%$ & $18.5 \%$ & $22 \%$ & $0.5 \%$ & $0 \%$ & $18 \%$ & $0 \%$ & $0 \%$ & $0 \%$ & $4.5 \%$ & $100 \%$ \\
\hline & 171 & 18 & 39 & 1 & 1 & 34 & 4 & 0 & 0 & 37 & 305 \\
\hline & \multicolumn{10}{|c|}{ S4 } & $100 \%$ \\
\hline & 146 & 30 & 107 & 0 & 5 & 3 & 72 & 0 & 0 & 2 & 365 \\
\hline \multicolumn{11}{|c|}{140} & $100 \%$ \\
\hline & 171 & 49 & 15 & 23 & 3 & 20 & 0 & 0 & 0 & 5 & 286 \\
\hline S6 & & & & & & & & & & & \\
\hline
\end{tabular}




\begin{tabular}{|c|c|c|c|c|c|c|c|c|c|c|c|}
\hline & $85.5 \%$ & $24.5 \%$ & $7.5 \%$ & $11.5 \%$ & $1.5 \%$ & $10 \%$ & $0 \%$ & $0 \%$ & $0 \%$ & $2.5 \%$ & $100 \%$ \\
\hline \multirow{2}{*}{ S7 } & 183 & 53 & 25 & 28 & 1 & 4 & 3 & 0 & 0 & 18 & 315 \\
\hline & $91.5 \%$ & $26.5 \%$ & $12.5 \%$ & $14 \%$ & $0.5 \%$ & $2 \%$ & $1.5 \%$ & $0 \%$ & $0 \%$ & $9 \%$ & $100 \%$ \\
\hline S8 & 177 & 18 & 51 & 0 & 0 & 41 & 15 & 0 & 2 & 10 & 314 \\
\hline \multirow{3}{*}{ S9 } & $88.5 \%$ & $9 \%$ & $25.5 \%$ & $0 \%$ & $0 \%$ & $20.5 \%$ & $7.5 \%$ & $0 \%$ & $1 \%$ & $5 \%$ & $100 \%$ \\
\hline & 175 & 16 & 44 & 5 & 0 & 7 & 33 & 7 & 2 & 19 & 308 \\
\hline & $87.5 \%$ & $8 \%$ & $22 \%$ & $2.5 \%$ & $0 \%$ & $3.5 \%$ & $16.5 \%$ & $3.5 \%$ & $1 \%$ & $9.5 \%$ & $100 \%$ \\
\hline \multirow{3}{*}{$\mathrm{S} 10$} & 140 & 21 & 93 & 1 & 1 & 31 & 4 & 0 & 1 & 0 & 292 \\
\hline & $70 \%$ & $10.5 \%$ & $46.5 \%$ & $0.5 \%$ & $0.5 \%$ & $15.5 \%$ & $2 \%$ & $0 \%$ & $0 \%$ & $0 \%$ & $100 \%$ \\
\hline & 1,678 & 273 & 366 & 71 & 12 & 214 & 138 & 7 & 5 & 232 & 2,996 \\
\hline Total & $83.9 \%$ & $13.7 \%$ & $18.3 \%$ & $3.6 \%$ & $0.6 \%$ & $10.75 \%$ & $6.9 \%$ & $0.4 \%$ & $0.3 \%$ & $11.6 \%$ & $100 \%$ \\
\hline
\end{tabular}

Note: $a=$ Thanking, $b=$ Appreciation, $c=$ Positive feelings, $d=$ Apology, $e=$ Recognition of imposition, $f=$ Repayment, $g=$ Alerters, $h=$ No gratitude, $i=$ Wishing, $j=$ others.

\subsection{Using of Politeness Strategies}

Speech acts have been examined as 'linguistic carriers of politeness' (Meier 1996: 345), and specific speech acts, such as thanking, are considered to embody politeness. This study examined how Arab speakers and native English speakers employ politeness through thanking speech act strategies. Table 3 summarizes the most frequently used of politeness strategies in Arabic. 90.35\% of 200 Arabic responses contained negative politeness, while $10.45 \%$ contained positive politeness. While Table 4 summarizes the most frequently used of politeness strategies in the English language. $90.35 \%$ of the responses in 200 English responses contained negative politeness, while $22.05 \%$ contained positive politeness. Both ENS and ANS preferred to use negative politeness strategies over positive politeness strategies in most situations, at a rate of $90.35 \%$. Using negative politeness may assume that others are subjected to restrictions and interference with their social space, which increase the situation's embarrassment. In most situations, ENS and ANS employed a strategy of thanking, appreciating, apologizing, and wishing, which is regarded as negative politeness.

Table (4): Politeness Strategies for Arabic Language ( $\mathrm{N}=200)$

\begin{tabular}{|c|c|c|c|c|c|c|c|c|c|c|c|}
\hline $\begin{array}{l}\text { Strategies for } \\
\text { doing FTAS }\end{array}$ & S1 & S2 & S3 & S4 & S5 & S6 & S7 & S8 & S9 & S10 & Total \\
\hline \multirow{3}{*}{$\begin{array}{c}\text { Positive } \\
\text { Politeness }\end{array}$} & 9 & 60 & 23 & 40 & 4 & 15 & 9 & 21 & 10 & 18 & 209 \\
\hline & & & & & & & & & & & \\
\hline & $4.5 \%$ & $30 \%$ & $11.5 \%$ & $20 \%$ & $2 \%$ & $7.5 \%$ & $4.5 \%$ & $10.5 \%$ & $5 \%$ & $9 \%$ & $10.45 \%$ \\
\hline \multirow{3}{*}{$\begin{array}{l}\text { Negative } \\
\text { Politeness }\end{array}$} & 188 & 175 & 181 & 185 & 157 & 188 & 186 & 183 & 185 & 179 & 1,807 \\
\hline & & & & & & & & & & & \\
\hline & $94 \%$ & $87.5 \%$ & $90.5 \%$ & $92.5 \%$ & $78.5 \%$ & $94 \%$ & $93 \%$ & $91.5 \%$ & $92.5 \%$ & $89.5 \%$ & $90.35 \%$ \\
\hline
\end{tabular}

Table (5): Politeness Strategies for English Language (N=200)

\begin{tabular}{|c|c|c|c|c|c|c|c|c|c|c|c|}
\hline $\begin{array}{l}\text { Strategies for } \\
\text { doing FTAs }\end{array}$ & S1 & S2 & S3 & S4 & S5 & S6 & S7 & S8 & S9 & $\mathrm{S} 10$ & Total \\
\hline Positive & 25 & 143 & 45 & 70 & 5 & 25 & 21 & 50 & 26 & 31 & 441 \\
\hline Politeness & $12.5 \%$ & $71.5 \%$ & $22.5 \%$ & $35 \%$ & $2.5 \%$ & $12.5 \%$ & $10.5 \%$ & $25 \%$ & $13 \%$ & $15.5 \%$ & $22.05 \%$ \\
\hline \multirow{2}{*}{$\begin{array}{l}\text { Negative } \\
\text { Politeness }\end{array}$} & 190 & 168 & 185 & 182 & 161 & 194 & 199 & 187 & 184 & 157 & 1,807 \\
\hline & $95 \%$ & $84 \%$ & $92.5 \%$ & $91 \%$ & $80.5 \%$ & $97 \%$ & $99.5 \%$ & $93.5 \%$ & $92 \%$ & $78.5 \%$ & $90.35 \%$ \\
\hline
\end{tabular}

\subsection{Use of thanking strategies by contextual variables}

In the DCT situations, two contextual variables were chosen: familiarity (i.e., social distance) and social status (i.e., power). The results analysis indicated that these two contextual variables significantly affect the number of ANS and ENS strategies. According to Figure 1, ENS and ANS employed more thanking strategy in high-familiarity than low-familiarity situations. ENS used a significantly more appreciate strategy in high-familiarity situations than ANS. Regardless of familiarity level, ENS and ANS used recognition the imposition and no gratitude strategy at a low rate. ANS used the wishing strategy significantly more than ENS. ENS and ANS used others strategy more frequently in high-familiarity than in low-familiarity situations. 


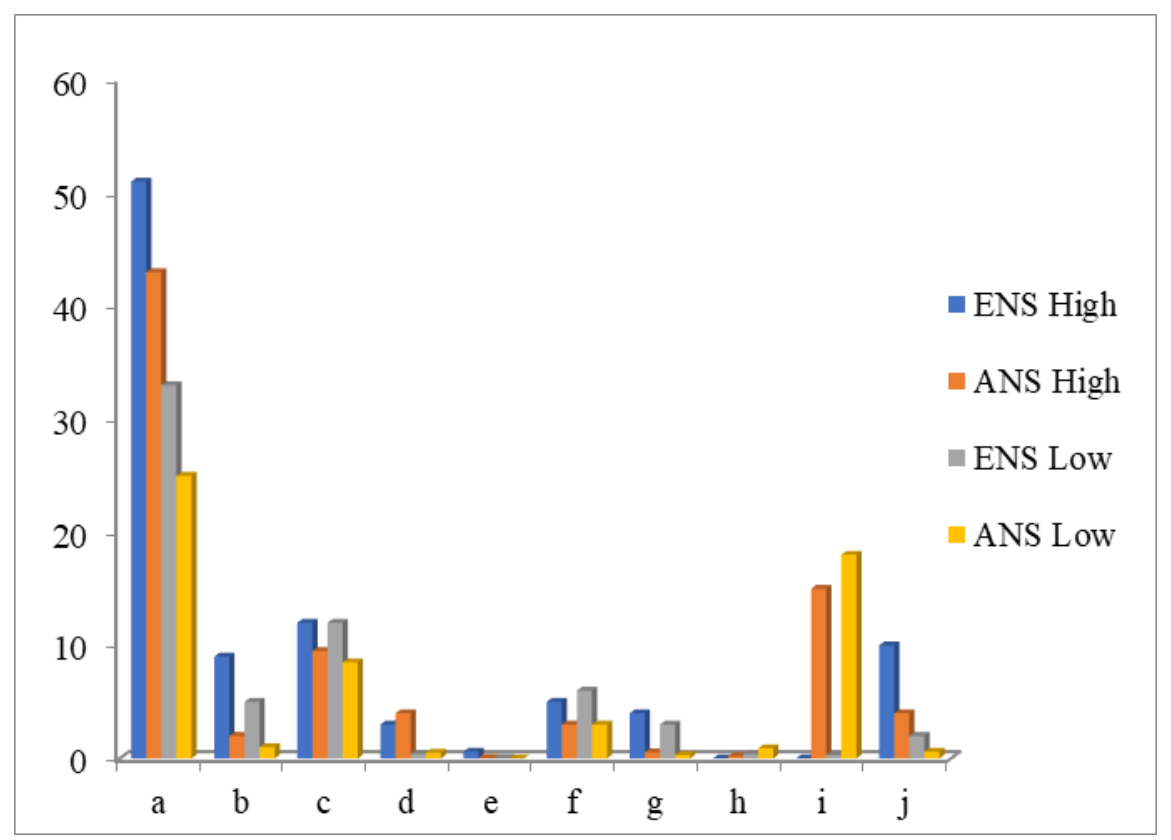

Figure (1): Frequency of Strategies by familiarity for ENS and ANS

Note: $a=$ Thanking, $b=$ Appreciation, $c=$ Positive feelings, $d=$ Apology, $e=$ Recognition of imposition, $f=$ Repayment, $g=$ Alerters, $h=$ No gratitude, $i=$ Wishing, $j=$ others.

Figure 2 shows that ENS and ANS used thanking strategy more frequently in equal status than in low-status situations; however, they used Positive feelings strategies equally in similar and low status situations. While ENS used the apology strategy less frequently in equal status situations than in low-status situations, ANS used it more frequently in equal status situations. ANS used the wishing strategy more frequently in situations of equal status than in low-status situations, whereas ENS did not. ENS and ANS used other strategy more frequently in equal status than low status.

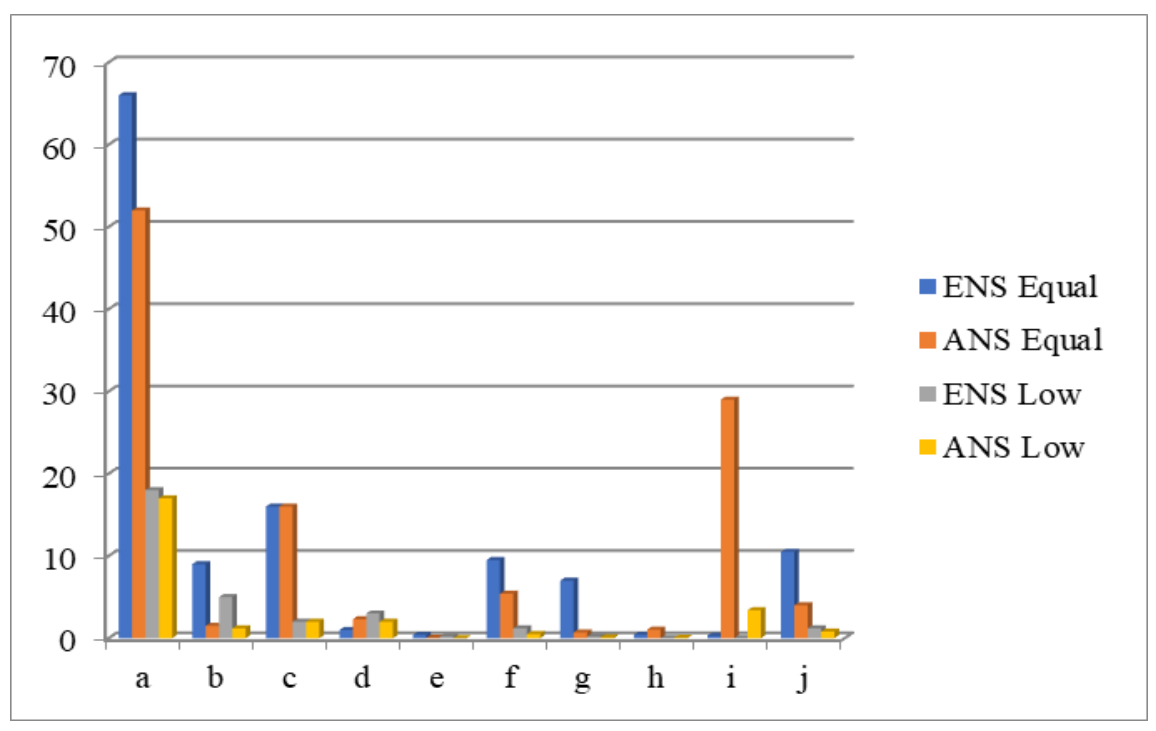

Figure (2): Frequency of Strategies by social status for ENS and ANS

Note: $a=$ Thanking, $b=$ Appreciation, $c=$ Positive feelings, $d=$ Apology, $e=$ Recognition of imposition, $f=$ Repayment, $g=$ Alerters, $h=$ No gratitude, $i=$ Wishing, $j=$ others.

To summarize, contextual variables have a significant influence on how ENS and ANS use the strategies. This may be due to different social influence on both groups. As each group has a special influence on the community in which they live, whether with their thoughts, behaviors or attitudes. The results show that the thanking strategy was used significantly more in high and equal status for ENS and ANS. Both groups almost didn't use the recognition of imposition and no gratitude strategy. The results also show that the other strategy is used significantly more in high and equal status for both ENS and ANS. 


\section{Implication}

In the future, there may be another cross-cultural study that investigates the speech act of thanking in Arabic and English based on a specific factor such as social distance. As Bogardus (1947) stated, "in social distance studies, the center of attention is on the feeling reactions of persons toward other persons and groups of people." It is noteworthy that the social distance affects much on producing any speech act, especially thanking. Additionally, it would be interesting to examine thanking in Arabic dialects concerning civilization's cultural influence and determine how close or far the dialect is from the standard Arabic language. Due to colonialism, there is a significant impact on the Arabic language in some countries in North Africa, making it difficult to understand. By contrast, the Arabic language for some countries of the Arabian Peninsula is much closer to standard Arabic.

\section{Conclusion}

The study found that the diversity of Arabic dialects does not affect the number of thanking strategies, as the English have more than the Arabic. It was noteworthy that the Arabs' religion significantly influences their way of speaking, with the wishing strategy (religious formulas) being a critical strategy for Arabs to express their sincerity and gratitude to the hearer in all situations, whether used alone or in combination with other strategies. Historically, language and religion were viewed as distinct and influential cultural components that interacted and influenced one another (Alsohaibani, 2017).

This has been confirmed by some Arab researchers, including (Bataineh, 2013; Al-Shaer 2013). When it came to politeness strategies, both ENS and ANS preferred negative politeness strategies over positive politeness strategies. It focuses on minimizing the FTA's particular imposition. Moreover, in linguistic politeness, it is considered as a deference strategy. As it recognizes the addressee's face wants. negative politeness strategies, entails thanking, appreciating, apologizing, and wishing strategy. Regarding contextual variables, it scored highly whether familiarity and social status influence the performance of thanking speech act.

\section{References}

1. Abbas, F., Anjum, K., \& Pasha, S. B. (2019). Speech act of apology by Pakistani English speakers through the theory of politeness. The Dialogue, 14(2): 196-213.

2. Al-Adaileh, B. A. M. (2007). The speech act of apology: A linguistic exploration of politeness orientation in British and Jordanian culture [Doctoral dissertation, University of Leeds]. White Rose eTheses Online.

3. Al-Khateeb, S. M. I. (2009). The speech act of thanking as a compliment response as used by the Arab speakers of English a comparative intercultural study [Master's thesis, An-Najah National University].

4. Al-Shaer, I. (2013). Speech acts in American English and Palestinian Arabic. International Journal of Language Learning and Applied Linguistics World, 4(1): 223-244.

5. Alsohaibani, A. (2017). Influence of Religion on Language Use: a sociopragmatic study on the influence of religion on speech acts performance (Doctoral dissertation, University of East Anglia).

6. Alabdali, T. S. (2019). Revisiting Brown and Levinson's Politeness theory: A Middle-Eastern perspective. Bulletin of Advanced English Studies, 2(2): 73-78. https://doi.org/10.31559/baes2019.2.2.3.

7. Alakrash, H. M., \& Bustan, E. S. (2020). Politeness strategies employed by Arab EFL and Malaysian ESL students in making request. International Journal of Academic Research in Business and Social Sciences, 10(6), 10-20. https://doi.org/10.6007/IJARBSS/v10-i6/7257.

8. Barešová, I. (2008). Politeness strategies in cross-cultural perspective: Study of American and Japanese employment rejection letters. Univerzita Palackého v Olomouci.

9. Bataineh, R. F. (2013). On congratulating, thanking, and apologizing in Jordanian Arabic and American English. Journal of Intercultural Communication, 32(1).

10. Beebe, L. M., \& Cummings, M. C. (2009). Natural speech act data versus written questionnaire data: How data collection method affects speech act performance. In S. Gass \& J. Neu (Eds.), Speech acts across cultures (pp. 65-88). De Gruyter Mouton.

11. Blum-Kulka, S., \& Olshtain, E. (1984). Requests and apologies: A cross-cultural study of speech act realization patterns (CCSARP) 1. Applied Linguistics, 5(3), 196-213. https://doi.org/10.1093/applin/5.3.196.

12. Bogardus, E. S. (1947). Measurement of personal-group relations. Sociometry, 10(4): 306-311. https://doi.org/10.2307/2785570.

13. Brown, P., \& Levinson, S. C. (1987). Politeness: Some universals in language usage. Cambridge University Press.

14. Burkhardt, A. (1990). Speech acts, meaning and intentions: Critical approaches to the philosophy of John R. Searle. De Gruyter.

15. Cheng, S. W. (2005). An exploratory cross-sectional study of interlanguage pragmatic development of expressions of 
gratitude by Chinese learners of English [Doctoral dissertation, The University of Iowa]. Iowa Research Online.

16. Cheng, S. W. (2010). A Corpus-Based Approach to the Study of Speech Act of Thanking. Concentric: Studies in Linguistics, 36(2).

17. EI-Zeini, N. (2001). Expressions of gratitude in Cairene Arabic: Pragma linguistic study. International Journal of ArabicEnglish Studies, 2(1):171-214.

18. Jumanto, J., Rizal, S. S., \& Nugroho, R. A. (2017). Acting the intangible: Hints of politeness in non-verbal form. English Language Teaching, 10(11): 111-118. https://doi.org/10.5539/elt.v10n11p111.

19. Katz, J. J. (1980). Propositional structure and illocutionary force: A study of the contribution of sentence meaning to speech acts. Harvard University Press.

20. Leech, G. N. (1983). Principles of pragmatics. Longman.

21. Mansor, F. A. (2017). Politeness and offering in Libyan Arabic hospitality [Doctoral dissertation, Sheffield Hallam University].

22. Meier, A. J. (1996). Two cultures mirrored in repair work. Multilingua, 15(2):149-169. https://doi.org/10.1515/mult.1996.15.2.149

23. Morsi, R. H. (2010). The speech act of thanking in Egyptian Arabic [Master's thesis, Ball State University].

24. Nouichi, F., \& Beghoul, Y. (2018). A comparative pragmatic study of eastern Algerian Arabic and English speech acts of thanking and greeting and responding to them [Doctoral dissertation, University Frères Mentouri Constantine].

25. Ohashi, J. (2013). Thanking and politeness in Japanese: Balancing acts in interaction. Springer.

26. Peterson, E. (2010). Perspective and politeness in Finnish requests. Pragmatics, 20(3): 401-423. https://doi.org/10.1075/prag.20.3.05pet.

27. Saberi, K. (2012). Routine politeness formulae in Persian: A socio-lexical analysis of greetings, leave-taking, apologizing, thanking and requesting [Doctoral dissertation, University of Canterbury].

28. Searle, J. R., Kiefer, F., \& Bierwisch, M. (Eds.). (1980). Speech act theory and pragmatics. D. Reidel.

29. Searle, J. R., Searle, P. G., Willis, S., \& Searle, J. R. (1969). Speech acts: An essay in the philosophy of language. Cambridge University Press.

30. Taha, M. A. (2015). Speech act of thanking in colloquial cairene Arabic and American English: A cross-cultural study. Journal of the Faculty of Education, 3(21): 27-58.

31. Watts, R., J, Ide, S., \& Ehlich, K. (Eds.). (2005). Politeness in language. De Gruyter Mouton. https://doi.org/doi:10.1515/9783110199819.

32. Wierzbicka, A. (2003). Cross-cultural pragmatics: The semantics of human interaction. De Gruyter Mouton. https://doi.org/doi:10.1515/9783110220964.

33. Yaqubi, M., Saeed, K. M., \& Khaksari, M. (2016). Conversational maxim view of politeness: Focus on politeness implicatures raised in performing Persian offers and invitations. Theory and Practice in Language Studies, 6(1): 52-58. https://doi.org/10.17507/tpls.0601.07. 


\section{Appendix One}

\section{The English Version of Discourse Completion Task}

\section{Dear respondents!}

A study is being conducted on Thanking strategies in Arabic and English for a master's degree in linguistics. Please read the following cases carefully and express your thanking in the actual conversation as if you were in the same position. The questionnaire takes no more than 3 minutes of your precious time. Appreciate your support!

Section 1:

1.Gender: Male $\square \quad$ Female

2. Age: less than 25 years old $\quad 25$ to 30 years old $\quad 31$ to 35 years old $\quad 36$ to 40

41 and above years old

3. Level of study: Bachelor Master postdoctoral Others

4.Nationality:

5. Department/Program:

Section 2:

6. You were sick and missed some lessons last week. So, you asked your colleague to lend you the notebook of lessons then he agreed. When you return the notebook to him, what would you say?

7. You went to buy some goods with your friend, and when you about to pay, you found that you forgot your wallet at home. Subsequently, your friend paid for you. After you got your purchases, what would you say?

8. You had traveled to a country, and you wanted to rent an apartment, but you couldn't speak their language. While you were passing by the street, you found a person of the same nationality as yours, so you asked him for help, and he gladly helped you by offering to translate then you rented an apartment. What would you say?

9. You needed to buy an essential book for your study, but you didn't find it. Then, you asked your friend to buy it for you from his country since it was published in his country, he agreed and bought it for you, then he posted it to you by post. After you got the book, what would you say?

10. Your birthday has come, but you forgot it because you were busy, then you were surprised that your friends prepared for you a birthday party. What would you say?

11. You were preparing a term paper for one of your courses, and you had finished writing it by the exact deadline, but a problem happened to your computer, and you need at least two days to fix it. So, you asked Professor John for more few days, and he agreed. When you handed in your paper to Professor John, what would you say?

12.You want to apply for a scholarship that requires two recommendation letters from two professors. You have already got the letter from one of them and the other teacher was on holiday. You embarrassedly sent him an email asking him to help with the recommendation letter. Kindly, he replied that there is no problem then he sent you the letter. After you got the letter, what would you say? Cheng

13. You went shopping and when you back home found that you lost your purse that has $100 \$$ and your ID card. After a while, you got a call from a person who found your wallet and wants to give it back to you. After you got your purse, what would you say?

14.You went to the park with your son suddenly your son disappeared, and you could not find him, after about an hour the security man came and brought him back to you, what would you say?

15. You had a traffic accident, and you lost a lot of blood, then you were taken to the hospital. You were in dire need of a rare blood donation. Someone you do not know came and donated for you. What would you say? 


\section{Appendix Two \\ The Arabic Version of Discourse Completion Task}

أعزاءي المشاركين!

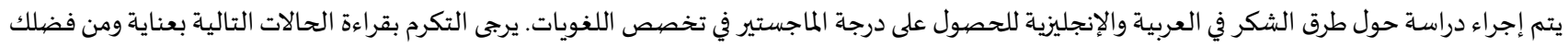

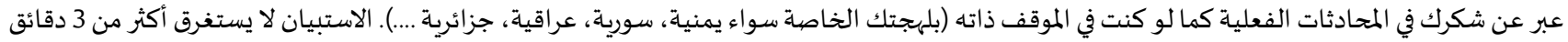
من وقتكم الثمين، ممتنة لدعمكم!

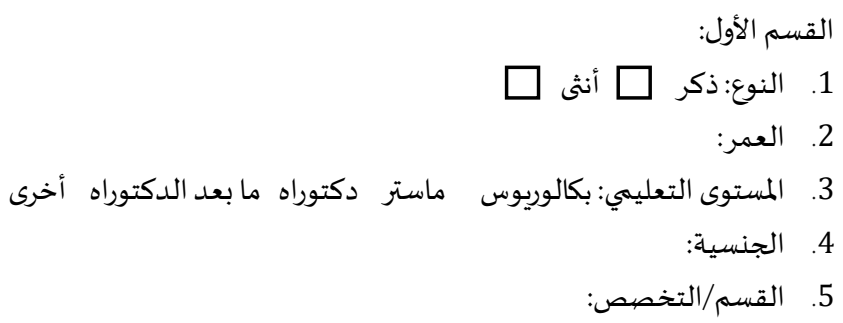

القسم الثاني:

6. أصبت بوعكة صحية فاضطررت للتغيب وفوتت بعض محاضرات الأسبوع الماضي فطلبت من زميلك أن يعيرك دفتر الملاحظات الخاص بالدروس ووافق، عندما تعيد اليه الملاحظات ماذا ستقول له؟ 7.ذهبت مع صديقك لشراء بعض الأغراض وعندما كنت على وشك الدفع أدركت أنك نسيت محفظتك في المنزل بعد ذلك دفع صديقك لك، بعد أن حصلت على أغراضك ماذا ستقول له؟

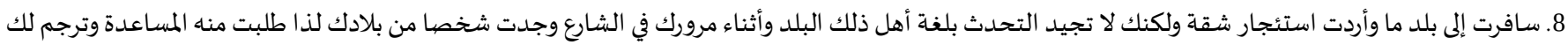
بكل سرور ثم استأجرت الشقة. ماذا ستقول له مأل

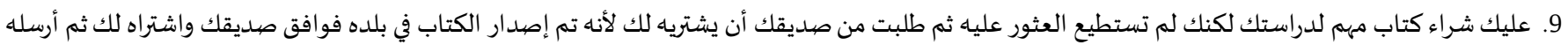

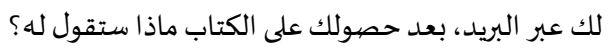
10. أتى موعد عيد ميلادك ولكنك لم تتذكره بسبب انشغالك بعد ذلك الك تتفاجآ بأن أصدقائك أعدوا لك ماذك حفلة عيد ميلاد. ماذا ستقول لهم؟

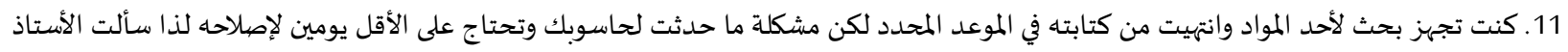

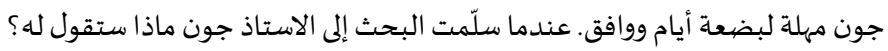

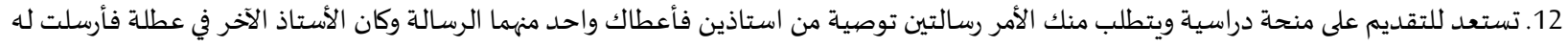

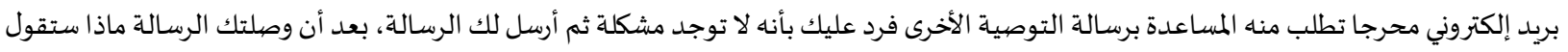

13. ذهبت للتسوق وعندما عدت للمنزل وجدت أنك فقدت محفظتك التي تحوي 100 دولار وهويتك الشخصية. بعد فترة من الوقت تلقيت مكالمة من شخصٍ وجد

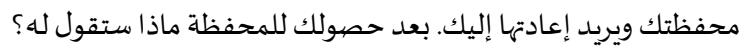

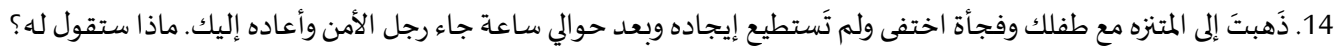

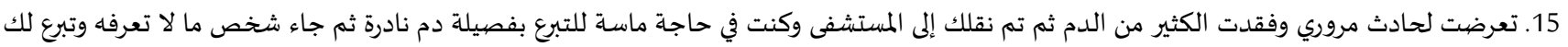
بالدم ماذا ستقول له ؟ 